\title{
The role of the adipocytokines vaspin and visfatin in vascular endothelial function and insulin resistance in obese children
}

\author{
Chunyan Yin, Wei Hu, Ming Wang and Yanfeng Xiao*
}

\begin{abstract}
Background: We measured the concentrations of the adipocytokines vaspin and visfatin in obese Chinese children. Furthermore, we studied the correlation of these adipocytokines with early-onset metabolic and vascular sequelae among these children.

Methods: A total of 244 children (160 obese and 84 lean) were included in this study. Vaspin and visfatin were detected using enzyme-linked immunosorbent assays. We also assayed other metabolic and cardiovascular parameters. The associations of serum vaspin and visfatin concentrations with metabolic and cardiovascular parameters were determined.

Results: We found a significant elevation in the concentrations of vaspin and visfatin in obese children compared to the concentrations in lean children. Additionally, we found a significant positive correlation between visfatin and vaspin levels, as well as inflammatory cell infiltration and markers of endothelial activation, but these factors did not affect insulin resistance in obese children. Multiple regression analyses confirmed that vaspin is the strongest predictor of higher tumour necrosis factor-a (TNF-a), interleukin-6 (IL-6), angiotensin-2 (Ang-2), vascular cellular adhesion molecule1 (VCAM-1), and E-selectin levels. We also found a significant association between visfatin and Ang-2, IL-6, VCAM-1, and E-selectin levels.
\end{abstract}

Conclusion: The adipocytokines vaspin and visfatin are significantly interrelated, and both adipocytokines play a role in vascular endothelial function and inflammation.

Keywords: Obese children, Vaspin, Visfatin, Endothelial dysfunction, Vascular inflammation

\section{Background}

Obesity is a growing health concern affecting more than 711.4 million individuals globally [1], among whom 107.7 million are children. Obesity is one of the major risk factors for a variety of chronic diseases, and its prevalence has been shown to increase with age in children [2]. Obesity leads to hypertension, insulin resistance, and diabetes [3, 4]. With the increasing prevalence of childhood obesity, these comorbidities have begun to develop in early childhood.

Due to a high body mass index (BMI), cardiovascular disease (CVD) alone accounted for 2.7 million deaths

\footnotetext{
* Correspondence: xiaoyanfenggroup@sina.com

Department of Pediatrics, The Second Affiliated Hospital of Xi'an Jiaotong University, No. 157 of West 5th Road, Xi'an, ShanXi 710049, People's Republic of China
}

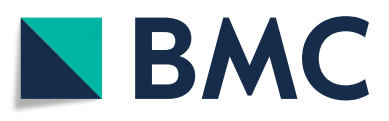

(c) The Author(s). 2019 Open Access This article is distributed under the terms of the Creative Commons Attribution 4.0 International License (http://creativecommons.org/licenses/by/4.0/), which permits unrestricted use, distribution, and reproduction in any medium, provided you give appropriate credit to the original author(s) and the source, provide a link to the Creative Commons license, and indicate if changes were made. The Creative Commons Public Domain Dedication waiver (http://creativecommons.org/publicdomain/zero/1.0/) applies to the data made available in this article, unless otherwise stated. CVD are endothelial dysfunction and subclinical inflammation in adults [5]. However, various biomarkers, including tumour necrosis factor- $\alpha$ (TNF- $\alpha)$, C-reactive protein (CRP), and cellular adhesion molecules (CAMs), have been reported to be significantly elevated in the plasma of obese children [6,7]. This elevation indicates the presence of vascular inflammation and endothelial dysfunction in childhood. Previous studies have shown that the occurrence of endothelial dysfunction and subclinical inflammation in childhood is considered to be the first sign of CVD development in adulthood [8].

Several adipocytokines have also been identified in the context of obesity [9]. Hence, understanding the diverse effects of distinct adipocytokines, as well as the relationships between these bioactive mediators, will help 
elucidate the underlying molecular basis of obesity-related diseases. Previous studies have shown that vaspin and visfatin are two adipocytokines that are closely associated with insulin resistance [10]. Vaspin belongs to a family of serine protease inhibitors (serpins), and it impairs glucose tolerance, leading to insulin resistance in obese mice [11]. In addition, elevated vaspin serum concentrations have been associated with obesity and impaired insulin sensitivity in adults [12]. Previous research reported that visfatin induces TNF- $\alpha$ and interleukin (IL)-6 in human monocytes [13]. It has also been demonstrated that recombinant visfatin directly binds to the insulin receptor (IR), leading to tyrosine phosphorylation and resulting in enhanced glucose uptake [14]. However, research conducted to understand the role of these adipocytokines in the pathogenesis of insulin resistance in the context of childhood obesity is limited. There has been no investigation to date to understand the association of vaspin and visfatin with endothelial dysfunction and vascular inflammation in obese children. Children either present earlier stages of pathogenesis or are relatively free of interfering comorbidities. In this regard, it is important to conduct studies in children to gain better insight into the association of vaspin and visfatin with the early stages of obesity-related disease.

In this study, we compared vaspin and visfatin levels between obese children and healthy controls. We also investigated the correlation of these two adipocytokines with one another. Finally, we investigated the association of these adipocytokines with metabolic syndrome, as this is a known cardiovascular risk factor and maker of endothelial activation in Chinese children.

\section{Methods}

\section{Subjects}

A total of 244 Chinese children, including 160 obese and 84 lean children, were included in this study. Children visiting the obesity clinic of the Pediatric Department of the Second Affiliated Hospital of Xi'an Jiao Tong University and the medical examination centre for routine check-ups were recruited as the study group and control group, respectively. Children with a BMI $>90$ th percentile and $<85$ th percentile for their age and sex were included in the obese and lean groups, respectively [15]. Children with endocrine disorders, genetic obesity syndromes, acute and chronic infectious disease, or autoimmune diseases were excluded from this study. We obtained approval for this study from the institutional ethics committee. The study was conducted in accordance with the Declaration of Helsinki and was approved by the ethics committee of the Second Affiliated Hospital of Xi'an JiaoTong University. All parents and children were carefully informed of the study protocol and provided written informed consent, which was duly signed before the subjects participated in the study.

\section{Anthropometric measurements}

Standing height and body weight were measured with children wearing light clothing without shoes. Waist and hip circumferences (WC and $\mathrm{HC}$, respectively) were measured to the nearest $0.1 \mathrm{~cm}$. The oscillometric device OMRON705IT was used to measure systolic and diastolic blood pressures (SBP and DBP, respectively) [16]. The Tanner criteria were used to determine pubertal developmental stages. Children were divided into two groups based on the criteria: prepubertal (Tanner stage I) and pubertal (Tanner stage II-V) [17]. None of the participants were taking any form of medication. We defined insulin resistance as HOMA-IR > 2 [18].

A body shape index (ABSI) was calculated using the following formula:

$\mathrm{ABSI}=\mathrm{WC}(\mathrm{m}) /\left[\mathrm{BMI}^{2 / 3}\left(\mathrm{~kg} / \mathrm{m}^{2}\right) \times \operatorname{Height}^{1 / 2}(\mathrm{~m})\right][19]$.

The visceral adiposity index (VAI) was calculated using the following formula:

$\mathrm{VAI}_{\text {male }}=\left[\mathrm{WC} \quad(\mathrm{cm}) / 39.68-1.88 \mathrm{BMI}\left(\mathrm{kg} / \mathrm{m}^{2}\right)\right][\mathrm{TGs}$ $(\mathrm{mmol} / \mathrm{L}) / 1.03,1.31 / \mathrm{HDL}(\mathrm{mmol} / \mathrm{L})]$.

$\mathrm{VAI}_{\text {female }}=\left[\mathrm{WC} \quad(\mathrm{cm}) / 36.58-1.89 \mathrm{BMI}\left(\mathrm{kg} / \mathrm{m}^{2}\right)\right][\mathrm{TGs}$ $(\mathrm{mmol} / \mathrm{L}) / 0.81,1.52 / \mathrm{HDL}(\mathrm{mmol} / \mathrm{L})]$.

TGs: triglycerides; HDL: high-density lipoprotein.

\section{Blood sampling and analysis}

Blood samples were taken in the morning at 8:00 AM after $12 \mathrm{~h}$ of overnight fasting. Blood specimens were centrifuged, and the remaining serum was stored at $80^{\circ} \mathrm{C}$. The oral glucose tolerance test (OGTT) was performed with $1.75 \mathrm{~g}$ glucose per $\mathrm{kg}$ of body weight (maximum of $75 \mathrm{~g}$ glucose) after a $12 \mathrm{~h}$ overnight fast. Blood specimens were obtained at 0 and $120 \mathrm{~min}$ to measure glucose and insulin concentrations. A double-antibody radioimmunoassay (RIA) was used to measure plasma insulin. An automatic analyser was used to determine the plasma glucose and lipid profiles (total cholesterol (TC), TGs, low-density lipoprotein (LDL), and HDL).

Serum IL- 6 and TNF- $\alpha$ concentrations were measured using a chemiluminescent enzyme assay (Fujirebio Inc., Tokyo, Japan). CRP was determined using an enzymatic latex-enhanced immunonephelometric assay (Dade Behring, Tokyo, Japan). Plasma levels of soluble VCAM-1, soluble ICAM, E-selectin, angiotensin-2 (Ang-2), adiponectin, and obestatin were detected using enzyme-linked immunosorbent assays (ELISAs) (USCN Life Science Inc., Wuhan, China). Vaspin and visfatin concentrations were also measured using ELISAs (Excell, Shanghai, China). The vaspin and visfatin inter- and intra-assay CVs were 4.8 and $7.2 \%$ and 5.6 and $8.3 \%$, respectively.

\section{Statistical analysis}

The normally distributed data are presented as the means \pm SEMs. Non-parametrically distributed parameters were log-transformed before analysis. Differences 
between two groups were assessed using Student's twotailed $t$-test or the $X^{2}$ test. General linear modelling was used to analyse the correlation between visfatin and vaspin with other biochemical parameters. Sex and age were controlled as confounding factors. For multiple regression analyses, anthropometric indicators and adipocytokines, as well as inflammatory factors including high-sensitivity CRP (hs-CRP), IL- 6 , and TNF- $\alpha$, and adhesion molecules including ICAM-1 and E-selectin, were used as the independent variables and dependent variables, respectively. Statistical analyses were performed using the Statistical Package for the Social Science (SPSS) 20.0 software (SPSS Inc., Chicago, IL, USA). $P<$ 0.05 was considered statistically significant.

\section{Results}

\section{Subject characteristics}

Table 1 shows the clinical characteristics of the study subjects. A total of 160 obese and 84 lean children were included in this study. As expected, there were no significant differences in age, height, or sex between the two groups. BMI, SDS-BMI, waist:hip ratio, WC, VAI, ABSI, WHtR, SBP, DBP, SDS-SBP, SDS-DBP, insulin, 2-h insulin, HOMA-IR, TGs, and LDL cholesterol were significantly elevated in the obese children. FPG, 2-h PG, TC, and HDL-cholesterol were not significantly different between the two groups, but plasma levels of adiponectin and obestatin were significantly lower in obese children than in lean children. We found significant elevations in plasma levels of VCAM-1, ICAM-1, E-selectin, and Ang-2 in obese children compared to the levels in lean children. In addition, obese children had higher plasma levels of IL6 , hs-CRP, and TNF- $\alpha$ than lean children. Serum visfatin and vaspin levels were significantly elevated in obese children compared to the levels in lean children (Table 1).

There were no significant differences between male and female children in any of the above indicators, including BMI, SDS-BMI, SDS-SBP, SDS-DBP, insulin, 2-h insulin, HOMA-IR, visfatin, vaspin VCAM-1, ICAM-1, E-selectin, and Ang-2 (Additional file 1: Table S1). There were no significant differences in visfatin, vaspin VCAM-1, ICAM1, E-selectin, and Ang-2 among participants in different Tanner stages (Additional file 2: Table S2).

We divided the obese children into an insulin resistance group and a non-insulin resistance group according to insulin HOMA-IR z-scores to evaluate the potential correlations of visfatin and vaspin with insulin resistance. We also compared differences in the above indicators between the two groups. We found that plasma levels of visfatin, vaspin, VCAM-1, ICAM-1, E-selectin, and Ang-2 were similar in the insulin resistance and non-insulin resistance groups (Additional file 3: Table S3).
Table 1 Clinical and laboratory characteristics of the study population

\begin{tabular}{|c|c|c|}
\hline Characteristic & Lean $(N=80)$ & Obese $(N=160)$ \\
\hline Age (y) & $10.31 \pm 2.45$ & $11.03 \pm 2.76$ \\
\hline BMI $\left(\mathrm{kg} / \mathrm{m}^{2}\right)$ & $17.35 \pm 2.05$ & $28.26 \pm 3.84^{b}$ \\
\hline SDS-BMI & $0.42 \pm 0.78$ & $2.85 \pm 0.92^{b}$ \\
\hline Weight (kg) & $38.65 \pm 7.26$ & $60.03 \pm 12.26^{b}$ \\
\hline Height (m) & $1.48 \pm 0.32$ & $1.52 \pm 0.28$ \\
\hline WHtR & $0.42 \pm 0.21$ & $0.65 \pm 0.26^{b}$ \\
\hline$W C(\mathrm{~cm})$ & $63.45 \pm 7.06$ & $93.56 \pm 11.28^{b}$ \\
\hline WHR & $0.79 \pm 0.06$ & $0.96 \pm 0.07^{b}$ \\
\hline $\mathrm{SBP}(\mathrm{mm} \mathrm{Hg})$ & $92.2 \pm 5.6$ & $108.6 \pm 12.7^{b}$ \\
\hline $\mathrm{DBP}(\mathrm{mm} \mathrm{Hg})$ & $76.5 \pm 3.6$ & $80.8 \pm 4.5^{\mathrm{a}}$ \\
\hline SDS-SBP & $1.49 \pm 0.83$ & $1.91 \pm 0.92^{b}$ \\
\hline SDS-DBP & $0.93 \pm 0.41$ & $1.22 \pm 0.73^{b}$ \\
\hline $\mathrm{FPG}(\mathrm{mmol} / \mathrm{L})$ & $4.36 \pm 0.82$ & $5.13 \pm 0.63$ \\
\hline 2-h PG (mmol/L) & $6.08 \pm 1.03$ & $6.83 \pm 1.27$ \\
\hline Insulin (IU/mL) & $12.0 \pm 2.9$ & $15.8 \pm 4.9^{a}$ \\
\hline 2-h Insulin (IU/mL) & $73.5 \pm 8.5$ & $79.1 \pm 11.2^{\mathrm{a}}$ \\
\hline HOMA-IR & $2.63(1.56,4.38)$ & $3.29(2.21,5.69)^{a}$ \\
\hline $\mathrm{TC}(\mathrm{mmol} / \mathrm{L})$ & $3.94 \pm 0.63$ & $3.89 \pm 0.55$ \\
\hline TGs (mmol/L) & $1.05 \pm 0.31$ & $1.43 \pm 0.62^{a}$ \\
\hline $\mathrm{HDL}-\mathrm{C}(\mathrm{mmol} / \mathrm{L})$ & $1.41 \pm 0.46$ & $1.39 \pm 0.35$ \\
\hline LDL-C (mmol/L) & $2.31 \pm 0.93$ & $2.46 \pm 1.01^{a}$ \\
\hline Adiponectin $(\mu \mathrm{g} / \mathrm{mL})$ & $11.28 \pm 1.53$ & $6.38 \pm 0.96^{b}$ \\
\hline Obestatin $(\mathrm{pg} / \mathrm{mL})$ & $236.32 \pm 30.54$ & $135.04 \pm 24.36^{b}$ \\
\hline Vaspin $(\mu \mathrm{g} / \mathrm{mL})$ & $4.87 \pm 0.93$ & $10.81 \pm 1.07^{b}$ \\
\hline Visfatin $(\mu \mathrm{g} / \mathrm{mL})$ & $36.54 \pm 9.31$ & $73.60 \pm 14.86^{b}$ \\
\hline hsCRP (ng/mL) & $1086.58 \pm 165.61$ & $1423.05 \pm 221.36^{b}$ \\
\hline $\mathbb{I L}-6(p g / m L)$ & $18.34 \pm 4.29$ & $32.42 \pm 6.71^{b}$ \\
\hline TNF-a (ng/mL) & $25.16 \pm 5.34$ & $50.24 \pm 13.43^{b}$ \\
\hline ICAM-1 $(\mu \mathrm{g} / \mathrm{mL})$ & $6.21 \pm 1.14$ & $11.36 \pm 1.56^{b}$ \\
\hline VCAM-1 $(\mu \mathrm{g} / \mathrm{mL})$ & $153.49 \pm 22.53$ & $251.34 \pm 38.57^{b}$ \\
\hline Ang-2 (pg/mL) & $83.56 \pm 10.28$ & $121.38 \pm 16.58^{b}$ \\
\hline E-selectin $(n g / m L)$ & $15.36 \pm 3.59$ & $32.53 \pm 9.05^{b}$ \\
\hline
\end{tabular}

Abbreviations: BMI, Body mass index; SDS-BMI, BMI s.d. score; WHtR, Waistheight ratio; VAl, Visceral adiposity index; $A B S I$, A body shape index; $W C$, waist circumference; WHR, Waist-to-hip ratio; $S B P$, Systolic blood pressure; $D B P$, Diastolic blood pressure; SDS-SBP, SBP s.d. score; SDS-DBP, DBP s.d. score; FPG, Fasting plasma glucose; HDL-C, High-density lipoprotein cholesterol; HOMA-IR, Homoeostasis model of insulin resistance; $L D L-C$, Low-density lipoprotein; $T C$, Total cholesterol; TGs, Triglycerides; TNF- $\alpha$, Tumour necrosis factor- $a$; $h s C R P$, High-sensitivity C-reactive protein; ICAM-1, Intercellular adhesion molecule-1; IMT, Intima-media thickness; VCAM-1, Vascular cell adhesion molecule-1; Ang-2, angiotensin-2

Data are expressed as the mean \pm s.d. or median (25th percentile, 75th percentile). ${ }^{\mathrm{a} P}<0.05$; ${ }^{\mathrm{b}} P<0.01$ compared with obese children 


\section{Relationship of serum vaspin and visfatin levels with other parameters}

Table 2 shows the correlations of serum visfatin and vaspin with other indicators in obese children. Significant positive correlations were detected between vaspin and SDS-BMI, BMI, hsCRP, IL-6, TNF- $\alpha$, VCAM1, ICAM-1, Ang-2, and E-selectin levels in the single linear correlation analysis. A similar difference was also found for visfatin.

Table 2 Simple linear regression analysis using vaspin and visfatin as independent variables in obese children

\begin{tabular}{|c|c|c|c|c|}
\hline \multirow[t]{2}{*}{ Variable } & \multicolumn{2}{|c|}{ Vaspin $(\mu \mathrm{g} / \mathrm{mL})$} & \multicolumn{2}{|c|}{ Visfatin $(\mu \mathrm{g} / \mathrm{mL})$} \\
\hline & $\beta(r)$ & $P$ & $\beta(r)$ & $P$ \\
\hline \multicolumn{5}{|c|}{ Anthropometric Parameters } \\
\hline $\mathrm{BMI}\left(\mathrm{kg} / \mathrm{m}^{2}\right)$ & 0.468 & 0.012 & 0.523 & 0.008 \\
\hline SDS-BMI & 0.519 & 0.009 & 0.601 & 0.005 \\
\hline$W C(\mathrm{~cm})$ & 0.244 & 0.045 & 0.258 & 0.041 \\
\hline WHR & 0.122 & 0.094 & 0.182 & 0.075 \\
\hline $\mathrm{WHtR}$ & -0.045 & 0.703 & 0.055 & 0.644 \\
\hline VAl & -0.019 & 0.872 & 0.002 & 0.985 \\
\hline$A B S I$ & 0.061 & 0.606 & 0.032 & 0.784 \\
\hline \multicolumn{5}{|l|}{ Metabolic parameters } \\
\hline $\mathrm{FPG}(\mathrm{mmol} / \mathrm{L})$ & -0.135 & 0.259 & -0.145 & 0.224 \\
\hline $2 \mathrm{~h} \mathrm{FPG} \mathrm{(mmol/L)}$ & 0.147 & 0.089 & 0.106 & 0.133 \\
\hline Insulin (pmol/L) & -0.196 & 0.085 & -0.218 & 0.072 \\
\hline 2-h Insulin (IU/mL) & 0.224 & 0.064 & 0.187 & 0,073 \\
\hline Ln HOMA-IR & -0.217 & 0.067 & -0.223 & 0.060 \\
\hline LDL-C (mmol/L) & -0.205 & 0.052 & -0.019 & 0.860 \\
\hline $\mathrm{HDL}-\mathrm{C}(\mathrm{mmol} / \mathrm{L})$ & 0.032 & 0.966 & 0.046 & 0.721 \\
\hline Ln TGs (mmol/L) & 0.021 & 0.862 & 0.033 & 0.784 \\
\hline $\mathrm{TC}(\mathrm{mmol} / \mathrm{L})$ & 0.201 & 0.090 & 0.188 & 0.113 \\
\hline \multicolumn{5}{|c|}{ Endothelial and inflammatory markers } \\
\hline $\mathrm{SBP}(\mathrm{mm} \mathrm{Hg})$ & 0.002 & 0.987 & 0.004 & 0.970 \\
\hline $\mathrm{DBP}(\mathrm{mm} \mathrm{Hg})$ & 0.023 & 0.848 & 0.073 & 0.573 \\
\hline SDS-SBP & 0.052 & 0.654 & 0.038 & 0.753 \\
\hline SDS-DBP & -0.053 & 0.653 & 0.062 & 0.603 \\
\hline Ang-2 (pg/mL) & 0.914 & 0.000 & 0.933 & 0.000 \\
\hline Adiponectin $(\mu \mathrm{g} / \mathrm{mL})$ & 0.019 & 0.857 & -0.088 & 0.456 \\
\hline Obestatin (pg/mL) & 0.060 & 0.612 & 0.034 & 0.766 \\
\hline TNF-a $(p g / m L)$ & 0.724 & 0.000 & 0.733 & 0.000 \\
\hline hsCRP (ng/mL) & 0.621 & 0.000 & 0.633 & 0.000 \\
\hline IL-6 (pg/mL) & 0.739 & 0.000 & 0.736 & 0.000 \\
\hline ICAM-1 ( $\mu \mathrm{g} / \mathrm{mL})$ & 0.933 & 0.000 & 0.953 & 0.000 \\
\hline E-selectin (ng/mL) & 0.843 & 0.000 & 0.896 & 0.000 \\
\hline VCAM-1 $(\mu \mathrm{g} / \mathrm{mL})$ & 0.772 & 0.000 & 0.726 & 0.000 \\
\hline
\end{tabular}

Multiple regression analysis to determine associations of vaspin and vastatin in the Chinese obese cohort

Using multiple regression analyses, we found that vaspin was an independent predictor of hsCRP and IL-6, explaining 8 and $4 \%$ of hsCRP and IL- 6 variability, respectively. We also found that SDS-BMI was the strongest predictor of hsCRP and IL-6, contributing 29 and $20 \%$ to the variability, respectively. Moreover, we confirmed visfatin as an independent predictor of TNF- $\alpha$ and IL-6 in addition to SDS-BMI and WC. Finally, we confirmed that both vaspin and visfatin were the strongest predictors of ICAM-1, E-selectin, and Ang-2 levels (Tables 3 and 4).

\section{The association between visfatin and vaspin levels in obese children}

We determined the associations between serum visfatin and vaspin levels using simple regression analysis. We found a significant positive correlation between the serum levels of visfatin and vaspin in obese children $(r=0.412$, $P<0.001$ ) (Fig. 1).

\section{Discussion}

In our study, we first determined the differences in two adipocytokines, vaspin and visfatin, between lean and obese Chinese children. Obese children in our study showed significantly elevated serum visfatin and vaspin

Table 3 Multiple regression analyses of independent associations of vaspin and visfatin levels with inflammatory parameters in the Chinese Obese Cohort $(N=160)$

\begin{tabular}{|c|c|c|c|c|}
\hline \multicolumn{5}{|l|}{ Variables } \\
\hline Dependent & Independent & Parameter & $\beta$ & $P$ \\
\hline \multirow[t]{6}{*}{ TNF-a } & \multirow{6}{*}{$\begin{array}{l}\text { SDS- BMI, WC, vaspin, visfatin } \\
\text { hsCRP, IL-6 }\end{array}$} & SDS- BMI & 0.523 & 0.000 \\
\hline & & WC & 0.285 & 0.002 \\
\hline & & vaspin & 0.367 & 0.000 \\
\hline & & visfatin & 0.132 & 0.058 \\
\hline & & IL-6 & 0.087 & 0.472 \\
\hline & & hsCRP & 0.066 & 0.574 \\
\hline \multirow[t]{6}{*}{ hsCRP } & \multirow{6}{*}{$\begin{array}{l}\text { SDS-BMI,WC, vaspin,visfatin, TNF- } \\
\text { a, IL-6 }\end{array}$} & SDS- BMI & 0.582 & 0.000 \\
\hline & & WC & 0.228 & 0.003 \\
\hline & & vaspin & 0.205 & 0.006 \\
\hline & & visfatin & 0.105 & 0.085 \\
\hline & & TNF-a & 0.079 & 0.568 \\
\hline & & IL-6 & 0.045 & 0.637 \\
\hline \multirow[t]{6}{*}{ IL-6 } & \multirow{6}{*}{$\begin{array}{l}\text { SDS-BMI,WC, } \\
\text { vaspin,visfatin, TNF-a, hsCRP }\end{array}$} & SDS- BMI & 0.638 & 0.000 \\
\hline & & WC & 0.241 & 0.002 \\
\hline & & vaspin & 0.184 & 0.038 \\
\hline & & visfatin & 0.427 & 0.000 \\
\hline & & TNF-a & 0.079 & 0.532 \\
\hline & & hsCRP & 0.034 & 0.876 \\
\hline
\end{tabular}


Table 4 Multiple regression analyses of independent associations of vaspin and visfatin levels with endothelial parameters in the Chinese Obese Cohort $(\mathrm{N}=160)$

\begin{tabular}{|c|c|c|c|c|}
\hline \multicolumn{5}{|l|}{ Variables } \\
\hline Dependent & Independent & Parameter & $\beta$ & $P$ \\
\hline \multirow[t]{6}{*}{ ICAM-1 } & SDS- BMI, WC, vaspin, visfatin, E-selectinAng-2 & SDS- BMI & 0.435 & 0.000 \\
\hline & & WC & 0.187 & 0.037 \\
\hline & & vaspin & 0.326 & 0.000 \\
\hline & & visfatin & 0.288 & 0.002 \\
\hline & & E-selectin & 0.075 & 0.514 \\
\hline & & Ang-2 & 0.053 & 0.731 \\
\hline \multirow[t]{6}{*}{ E-selectin } & SDS-BMI,WC, vaspin,visfatin, ICAM-1, Ang-2 & SDS- BMI & 0.369 & 0.000 \\
\hline & & WC & 0.215 & 0.004 \\
\hline & & vaspin & 0.174 & 0.042 \\
\hline & & visfatin & 0.228 & 0.003 \\
\hline & & ICAM-1 & 0.067 & 0.612 \\
\hline & & Ang-2 & 0.032 & 0.893 \\
\hline \multirow[t]{6}{*}{ Ang-2 } & SDS-BMI,WC, vaspin,visfatin, ICAM-1, E-selectin & SDS- BMI & 0.337 & 0.000 \\
\hline & & WC & 0.274 & 0.003 \\
\hline & & vaspin & 0.185 & 0.032 \\
\hline & & visfatin & 0.164 & 0.043 \\
\hline & & ICAM-1 & 0.058 & 0.729 \\
\hline & & E-selectin & 0.029 & 0.916 \\
\hline
\end{tabular}

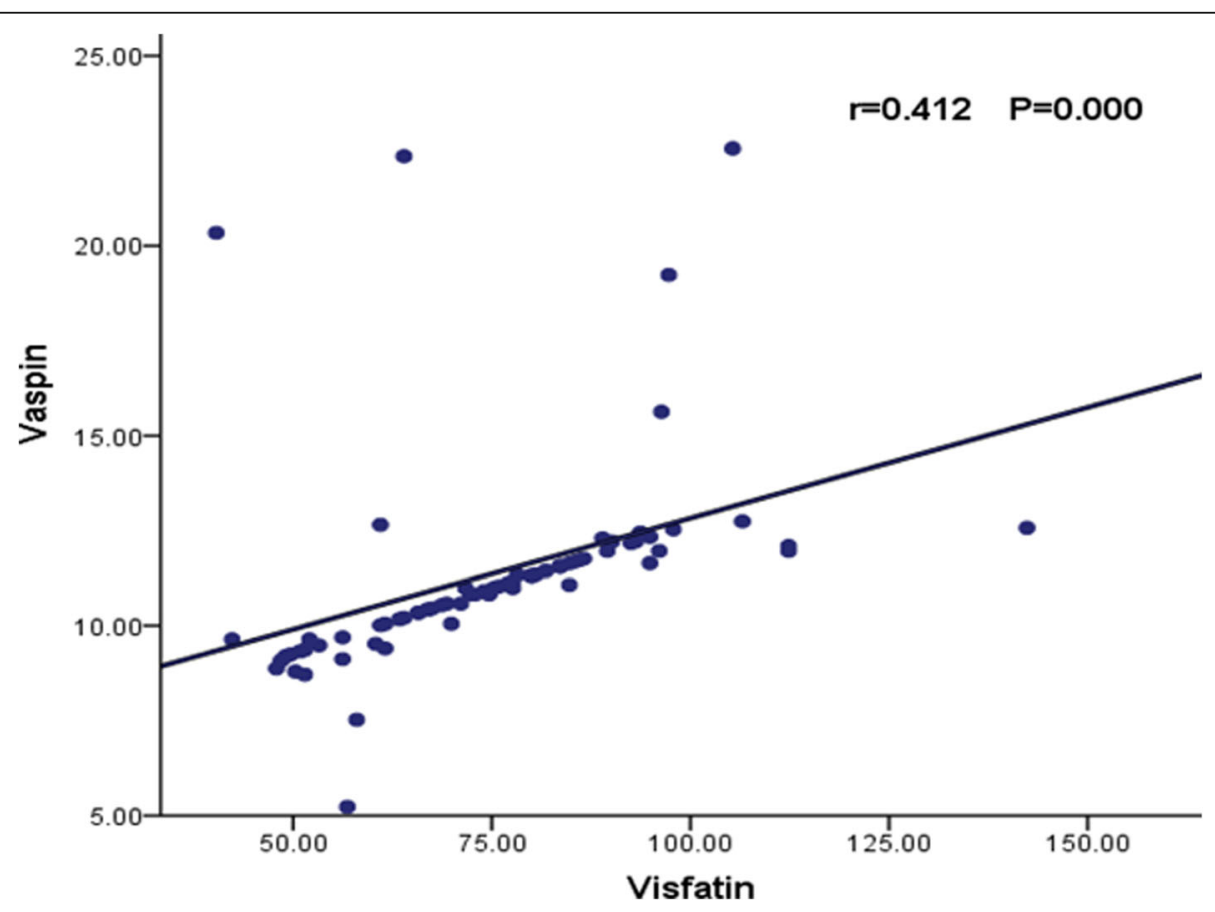

Fig. 1 Associations between visfatin and vaspin levels in obese children. Data are expressed as mean \pm s.d 
levels compared to the levels in lean controls. Next, we further studied the correlations of serum levels of vaspin and visfatin with vascular endothelial activity. We found a significant positive correlation of vaspin and visfatin levels with inflammatory and endothelial parameters, including IL-6, TNF- $\alpha$, hsCRP, VCAM-1, ICAM-1, Ang-2, and E-selectin. Our multiple regression analyses independently confirmed that both vaspin and visfatin levels were associated with SDS-BMI, Ang-2, IL-6, VCAM-1, and E-selectin. Finally, we determined the association between visfatin and vaspin levels in obese children and found that these two adipocytokines were significantly and positively correlated. The results presented here indicate that the adipocytokines visfatin and vaspin play an important role in endothelial dysfunction and vascular inflammation, but they do not affect insulin resistance.

We found that vaspin and visfatin levels were significantly elevated and positively correlated with SDS-BMI and BMI in obese children. There were some differences from the results of studies conducted with adult samples, which showed that plasma vaspin and visfatin levels were not only significantly and positively correlated with BMI but were also significantly associated with WC $[10,20]$. However, among these two anthropometric indicators, we found that vaspin and visfatin correlated with SDS-BMI but not with WC in obese children. In adults, WC is considered a better indicator of subcutaneous fat distribution [21], but in children, WC is still a controversial indicator for predicting cardiovascular risk because of the underlying relationship between WC and height.

Previous studies reported that vaspin and visfatin levels decrease concurrently with progression through puberty [22, 23]. However, we did not detect significant differences in vaspin and visfatin serum levels between prepubertal and pubertal children. The reason could be due to the narrow age range of the subjects and the small sample size of pubertal children in our study.

Various studies have investigated the relationship between levels of visfatin and insulin resistance in adults but with different results. Blüher indicated that plasma visfatin is related to insulin resistance, as assessed by HOMA-IR [24]. In contrast, Smith et al. and Varma et al. suggested that visfatin levels are not associated with insulin resistance $[25,26]$. Another study reported that visfatin directly binds and activates the insulin receptor to induce the phosphorylation of signal transduction proteins [13]. Therefore, based on our findings presented here, we propose that visfatin exerts insulinmimetic effects and thus enhances glucose uptake, improving insulin resistance. However, the physiological role of visfatin in the development of insulin resistance remains controversial. In our study, we did not detect an association between visfatin and FPG, 2-h PG, insulin, 2$\mathrm{h}$ insulin, or insulin resistance index. This discrepancy may be explained by the fact that high levels of insulin are usually observed in adults but not in children; hence, we did not find a relationship of vaspin and visfatin with more advanced disease conditions.

One of the main goals of this study was to evaluate the potential correlation of visfatin and vaspin with early obesity-related vascular alterations. Using multiple regression analyses, we confirmed that visfatin was an independent predictor of TNF- $\alpha$ and IL-6, in addition to SDS-BMI and WC. It is well known that obesity is a state of low-grade chronic inflammation. A low-grade inflammatory response is considered to be the first sign of the progression of obesity-related diseases, specifically vascular alterations $[27,28]$. Our results suggest that visfatin is involved in the pathological process of inflammation. Recent studies also suggested that soluble adhesion molecules, including ICAM-1, E-selectin, VCAM-1, and P-selectin, play an important role in the pathogenesis of atherosclerosis $[29,30]$. In previous studies, ICAM-1 and E-selectin were used as indicators of vascular endothelial activation in obese children [31]. From our multiple regression analyses, we determined the association of visfatin with ICAM-1, E-selectin, and Ang-2. Reports state that visfatin promotes the adhesion of monocytes to endothelial cells by upregulating their expression of adhesion molecules [32]. This report confirms the role of visfatin in the development of vascular endothelial dysfunction [33]. In contrast, we did not detect a correlation between plasma visfatin levels and soluble VCAM1. Whether circulating VCAM-1 levels are elevated in obese children, and whether this elevation has clinical significance for vascular injury, remains controversial. There has been no research conducted to understand the relationship between visfatin and Ang-2 in obese children. However, studies have confirmed that angiotensin plays an important and unique role in angiogenesis and vascular inflammation. Long-term elevation of circulating Ang-2 levels results in persistent microinflammation of the vascular endothelium [34].

Interestingly, it has been reported that adipocytokines that are secreted by adipose tissue stimulate vascular monocyte adhesion by activating ICAM-1 and E-selectin expression in endothelial cells [35]. In addition, many studies have discussed the link between vaspin and inflammation and atherosclerosis; however, the mechanism remains unclear [36, 37]. We observed an independent correlation between vaspin and increased hsCRP and IL-6 levels. Vaspin was correlated with hsCRP and IL-6 in obese children, indicating that these factors are involved in the systemic inflammatory response. However, published data reported a negative correlation between vaspin and CRP, demonstrating that vaspin has antiinflammatory and anti-atherosclerotic effects in the contexts of obesity-related inflammation and CVD [38, 39]. 
Therefore, the relationship between vaspin and inflammatory factors remains controversial and requires further investigation.

Not all adipokines are inflammatory factors that negatively affect the progression of obesity-related diseases. Some may play a protective role in the pathogenesis of CVD. The best example is adiponectin, which can exert substantial antiatherogenic actions [40]. However, we did not find a correlation between visfatin, vaspin, and adiponectin, which is in contrast to another study that demonstrated a significant negative association among these factors. In that report, multiple regression analysis used visfatin or vaspin as the dependent parameters and did not detect any significant correlation with adiponectin. Hence, we conclude that there is no relationship between the levels of these three adipokines. We speculate that the correlation between adiponectin and visfatin and vaspin reported in the literature may not be robust. However, we found a significant inter-association of vaspin and visfatin with inflammatory and vascular endothelial function parameters. This finding suggests that visfatin and vaspin are interrelated adipocytokines and play a role in both vascular endothelial function and inflammatory cell infiltration.

This study does have a limitation that should be noted. Specifically, our study included a small sample size, which prevents the generalization of our findings. However, this sample size was sufficient to verify a significant inter-association of vaspin and visfatin with inflammatory and endothelial parameters. We recommend that large-scale studies be conducted in the future to gain more insight into the role of adipocytokines in vascular endothelial dysfunction.

\section{Conclusion}

In conclusion, serum visfatin and vaspin levels in obese children are significantly higher than the levels in lean children. Visfatin and vaspin were significantly interrelated and associated with inflammatory and endothelial parameters. Thus, we conclude that both visfatin and vaspin play a role in vascular endothelial dysfunction and inflammatory infiltration.

\section{Supplementary informations}

Supplementary information accompanies this paper at https://doi.org/10. 1186/s12902-019-0452-6.

Additional file 1: Table S1. Clinical and biochemical features of male and female children.

Additional file 2: Table S2. Clinical and biochemical features of prepubertal and pubertal children

Additional file 3: Table S3. Anthropometric, metabolic, endothelial, and inflammatory parameters in obese children with IR and without IR

\section{Abbreviations}

ABSI: A body shape index; Ang-2: Angiopoietin-2; BMl: Body mass index; DBP: Diastolic blood pressure; FPG: Fasting plasma glucose; HDL-C: Highdensity lipoprotein cholesterol; HOMA-IR: Homeostasis model of insulin resistance; hSCRP: High- sensitivity C-reactive protein; ICAM-1: Intercellular adhesion molecule-1; IMT: Intima-media thickness; LDL-C: Low-density lipoprotein; SBP: Systolic blood pressure; SDS-BMI: BMI s.d. score; SDSDBP: DBP s.d. score; SDS-SBP: SBP s.d. score; TC: Total cholesterol; TG: Triglycerides; TNF-a: Tumour necrosis factor-a; VAl: Visceral adiposity index; VCAM-1: Vascular cell adhesion molecule-1; WC: Waist circumference; WHR: Waist-to-hip ratio; WHtR: Waist-height ratio

\section{Acknowledgements \\ Not applicable.}

\section{Ethics and consent to participate}

This study was approved by the Ethics Committee of the Second Affiliated Hospital of Xi'an JiaoTong University (No. 2016032). The study was in compliance with the Declaration of Helsinki for clinical research. All children and their parents both provided written informed consent before participating in the study.

\section{Authors' contributions}

YCY obtained funding. XYF designed the study. YCY and HW collected the data. WM was involved in data cleaning, mortality follow-up, and verification. YCY and WM analysed the data. All authors have read and approved the final manuscript.

\section{Authors' information}

Not applicable.

\section{Funding}

This work was funded by the Nature Science Foundation of China no. 81803262. The funding agencies had no role in the design of study, data collection and analysis, or presentation of the results.

\section{Availability of data and materials}

The datasets used or analysed during the current study are available from the corresponding author upon reasonable request.

\section{Consent for publication}

Not applicable.

\section{Competing interests}

The authors declare that they have no competing interests.

Received: 26 June 2019 Accepted: 30 October 2019

Published online: 26 November 2019

\section{References}

1. GBD 2015 Obesity Collaborators. Health effects of overweight and obesity in 195countries over 25 years. N Engl J Med. 2017;377:13-27.

2. Skinner AC, Perrin EM, Skelton JA. Prevalence of obesity and severe obesity in US children, 1999-2014. Obesity. 2016;24:1116-23.

3. Cornier MA, Dabelea D, Hernandez TL, Lindstrom RC, Steig AJ, Stob NR, et al. The metabolic syndrome. EndocrRev. 2008;29:777-822.

4. James WP. The epidemiology of obesity: the size of the problem. J InternMed. 2008;263:336-52.

5. Loader J, Roustit M, Baltzis D, Aristidis Veves A. Vascular Dysfunction, Inflammation, and Exercise in Diabetes. Diabetes and Exercise. Humana Press, Cham 2018;137-150

6. Daniels SR, Pratt CA, Hayman LL. Reduction of risk for cardiovascular disease inchildren and adolescents. Circulation. 2011;124(15):1673-86.

7. Nadeau KJ, Mahs DM, Daniels SR, Eckel RH. Childhood obesity and cardiovascular disease: links and prevention strategies. Nat Rev Cardiol. 2011;8:513-25.

8. Patel SR, Bellary S, Karimzad S, Gherghel D. Overweight status is associated with extensive signs of microvascular dysfunction and cardiovascular risk. Sci Rep. 2016;6:32282.

9. Divella R, Mazzocca A, Daniele A, Sabbà C, Paradiso A. Obesity, nonalcoholic fatty liver disease and adipocytokines network in promotion of cancer. Int J Biol Sci. 2019;15:610. 
10. El-Mesallamy HO, Kassem DH, El-Demerdash E, Amin Al. Vaspin andvisfatin/ Nampt are interesting interrelated adipokines playing a role in the pathogenesis of type 2 diabetes mellitus. Metabolism. 2011;60:63-70.

11. Heiker JT. Vaspin (serpinA12) in obesity, insulin resistance, and inflammation. J Pept Sci. 2014;20:299-306.

12. Youn BS, Klöting N, Kratzsch J, Lee N, Park JW, Song ES, et al. Serum vaspin concentrations in human obesity and type 2 diabetes. Diabetes. 2008;57:372-7.

13. Moschen AR, Kaser A, Enrich B, Mosheimer B, Theurl M, Niederegger $H$, et al. Visfatin, an adipocytokine with pro-inflammatory and immunomodulating properties. J Immunol. 2007;178:1748-58.

14. Fukuhara A, Matsuda M, Nishizawa M, Segawa K, Tanaka M, Kishimoto K, et al. Visfatin: a protein secreted byvisceral fat that mimics the effects of insulin. Science. 2005;307:426-30.

15. Li H, Ji C, Zong X, Zhang YQ. Body mass index growth curves for Chinese children and adolescents aged 0 to 18 years. Chin J Pediatr. 2009;47:493-8.

16. Stergiou GS, Yiannes NG, Rarra VC. Validation of the Omron 705IToscillometric device for home blood pressure measurement in children and adolescents: the Arsakion school study. Blood Press Monit. 2006;11:229-34.

17. Tanner JM. Growth and maturation during adolescence. Nutr Rev. 1981;39: 43-55.

18. Matthews DR, Hosker JP, Rudenski AS, NaylorD BA, Treacher DF, Turner RC. Homeostasis model assessment: insulin resistance and $\beta$-cell function from fasting plasma glucose and insulin concentrations in man. Diabetologia. 1985;28:412-9.

19. Ahima R S. A New Body Shape Index Predicts Mortality Hazard Independently of Body Mass Index. Obesity Epidemiology, Pathogenesis, and Treatment. Apple Academic Press. 2016; 129-153.

20. Takebayashi K, Suetsugu M, Wakabayashi S, Aso Y, Inukai T. Association between plasma visfatin and vascular endothelial function in patients with type 2 diabetes mellitus. Metabolism. 2007;56:451-8.

21. Chang SH, Beason TS, Hunleth JM, Colditz GA. A systematic review of body fat distribution and mortality in older people. Maturitas. 2012;72(3):175-91.

22. Jin $H$, Jiang B, Tang J, Lu W, Wang W, Zhou L, et al. Serum visfatin concentrations in obese adolescents and its correlation with age and highdensity lipoprotein cholesterol. Diabetes Res Clin Pract. 2008;79:412-8.

23. Körner A, Neef M, Friebe D, Erbs S, Kratzsch J, Dittrich K, et al. Vaspin is related to gender, puberty and deteriorating insulin sensitivity in children. Int J Obes. 2011;35:578.

24. Blüher M. Vaspin in obesity and diabetes: pathophysiological and clinical significance. Endocrine. 2012;41:176-82.

25. Smith J, Al-Amri M, Sniderman A, Cianflone K. Visfatin concentration in Asian Indians is correlated with high density lipoprotein cholesterol and apolipoprotein A1. Clin Endocrinol. 2006;65:667-72.

26. Varma V, Yao-Borengasser A, Rasouli N, Bodles AM, Phanavanh B, Lee MJ, et al. Human visfatin expression: relationship to insulin sensitivity, intramyocellular lipids, and inflammation. J Clin Endocrinol Metab. 2007;92: 666-72

27. Cooke AA, Connaughton RM, Lyons CL, McMorrow AM, Roche HM. Fatty acids and chronic low grade inflammation associated with obesity and the metabolic syndrome. Eur J Pharmacol. 2016;785:207-14.

28. Cabia B, Andrade S, Carreira MC, Casanueva FF, Crujeiras AB. A role for nove adipose tissue secreted factors in obesity related carcinogenesis. Obes Rev. 2016;17:361-76.

29. Hu Y, Liu K, Yan M, Zhang Y, Wang Y, Renet L. Effects and mechanisms of icariin on atherosclerosis. Int J Clin Exp Med. 2015:8:3585.

30. Ortiz Segura MC, del Río Navarro BE, Rodriguez Espino BA, Laurence AM, Fausto SM, Santiago V, et al. Abnormality of adipokines and endothelial dysfunction in Mexican obese adolescents with insulin resistance. Endocr Res. 2017:42:252-9.

31. Zhu Y, Shen T, Lin Y, Chen B, Ruan Y, Cao Y, et al. Astragalus polysaccharides suppress ICAM-1 andVCAM-1 expression in TNF-a-treated human vascular endothelial cells by blocking NF-kB activation. Acta Pharmacol Sin. 2013;34:1036.

32. Onat D, Brillon D, Colombo PC, Schmidt AM. Human vascular endothelial cells: a model system for studying vascular inflammation in diabetes and atherosclerosis. Current Diabetes Reports. 2011;11:193-202.

33. Kümpers P, David S, Haubitz M, Hellpap J, Horn R, Bröckeret V, et al. The Tie2 receptor antagonist angiopoietin2 facilitates vascular inflammation in systemic lupus erythematosus. Ann Therheumatic Dis. 2009;68:1638-43.
34. Mori T, Shinohara K, Wakatsuki A, Watanabe K, Fujimaki A Adipocytokines and endothelial function in preeclamptic women. Hypertens Res. 2010;33:250.

35. Kadoglou NPE, Gkontopoulos A, Kapelouzou A, Fotiadis G, Theofilogiannakos EK, Kottas G, et al. Serum levels of vaspin and visfatin in patients with coronary artery disease-Kozani study. Clin Chim Acta. 2011; 412:48-52.

36. Karbek B, Bozkurt NC, Topaloglu O, Aslan MS. Relationship of vaspin and apelin levels with insulin resistance and atherosclerosis in metabolic syndrome. Minerva Endocrinol. 2014;39:99-105.

37. Abu-Farha M, Behbehani K, Elkum N. Comprehensive analysis of circulating adipokines and hsCRP association with cardiovascular disease risk factors and metabolic syndrome in Arabs. Cardiovasc Diabetol. 2014;13:76.

38. Hao F, Zhang H, Zhu J, Kuang H, Yu Q, Bai M, et al. Association between vaspin level and coronary artery disease in patients with type 2 diabetes. Diabetes Res Clin Pract. 2016;113:26-32.

39. Reda E, Hassaneen S, El-Abhar HS. Novel trajectories of bromocriptine antidiabetic action: Leptin-IL-6/JAK2/p-STAT3/SOCS3, p-IR/p-AKT/GLUT4, PPAR- $y$ /adiponectin, Nrf2/PARP-1, and GLP-1. Front Pharmacol. 2018;9:771.

40. Kukla M, Mazur W, Bułdak RJ, Żwirska-Korczala K. Potential role of leptin, adiponectin andthree novel adipokines-visfatin, chemerin and vaspin-in chronic hepatitis. MolecularMedicine. 2011:17(11):1397.

\section{Publisher's Note}

Springer Nature remains neutral with regard to jurisdictional claims in published maps and institutional affiliations.
Ready to submit your research? Choose BMC and benefit from:

- fast, convenient online submission

- thorough peer review by experienced researchers in your field

- rapid publication on acceptance

- support for research data, including large and complex data types

- gold Open Access which fosters wider collaboration and increased citations

- maximum visibility for your research: over $100 \mathrm{M}$ website views per year

At BMC, research is always in progress.

Learn more biomedcentral.com/submissions 